\title{
SIMULATION OF HVAC TRANSMISSION LINE
}

\author{
H. Amreiz \\ London College UCK, \\ Division of Engineering \\ London, UK \\ h.amreiz@1cuck.uk
}

\author{
A. Janbey \\ London College UCK, \\ Division of Engineering \\ London, UK \\ a.janbey@lcuck.ac.uk
}

\author{
M. Darwish \\ Brunel University \\ Electronic and Computer Engineering \\ London, UK \\ mohamed.darwish@brunel.ac.uk
}

\begin{abstract}
The teaching of transmission lines at both undergraduate and postgraduate levels has been a popular topic in many electrical engineering courses. The teaching method used for delivering these courses was based on identifying the equivalent circuits and using mathematical analysis. Such approach will be difficult tasks for the students when dealing with a wide range of electrical components in a circuit. In the last decade or so circuit simulation has played a major role in facilitating the teaching of transmission lines at all levels.
\end{abstract}

The Simulated transmission line used for this paper is HVAC transmission line of $180 \mathrm{~km}$ length. The transmission line may be simulated as a 3-phase of $180 \mathbf{~ k m}$ length or a simulated single phase transmission line of $540 \mathrm{~km}$ length. The $180 \mathrm{~km}$ transmission line is divided into $6 \pi$ sections where each $\pi$ section is $30 \mathrm{~km}$ long. The line inductance is considered for every $30 \mathrm{~km}$ and the line capacitance considered for every $15 \mathrm{~km}$. The actual values of the line parameters (RLC) of $400 \mathrm{kV}$ transmission line are: $0.02978 \Omega / \mathrm{km}, 1.06 \mathrm{mH} / \mathrm{km}$ and $0.0146 \mu \mathrm{F} / \mathrm{km}$, respectively. The power carried by the transmission line is $250 \mathrm{~W}$.

Keywords: transmission line, Surge Impedance Loading (SIL), Simulation, Ferranti Effect

\section{INTRODUCTION}

At the early stages of the electrical age, generation, transmission and distribution of electricity was mainly as a direct current. However, the main disadvantage of DC systems was the fact that the voltage level could not easily be changed. This can only be done by using rotating machines which are very expensive. Currently, large power systems can only be utilized by using AC systems. At the power station, the electrical energy is transmitted at very high voltages and as a result it has to be stepped down at the substation in order for this energy to be distributed to different users through the use of transmission lines. In both design and operation of transmission lines, the main elements are: the voltage drop, the line losses and the efficiency of transmission lines.

The values that affect the transmission line parameters are: resistance, inductance and capacitance of the transmission line. This paper will outline the details of the simulating software used to find the constant of the transmission lines as well as the performance of these lines under loading condition. In addition to this the paper will investigate method used in determining the line constant, the sending end voltage, the real power, the reactive power and the maximum power, as well as calculations and formulation of the performance of the transmission line.

The simulator used in this investigation perform 9 simulating experiments, which are: The Ferranti effect, The ABCD parameters of $400 \mathrm{KV} \mathrm{HVAC} \mathrm{transmission} \mathrm{line,} \mathrm{The} \mathrm{surge}$ impedance loading, The shunt reactor compensation, The shunt capacitor compensation, The series reactor compensation, The over current relay, The over voltage relay and The under voltage relay.

\section{FACTORS AFFECTING THE TRANSMISSION LINE}

The power system and its performance will largely depend on the performance of transmission line which is incorporated in the system. The transmission line and its performance depends on the series resistance $\mathrm{R}$ and the inductance $\mathrm{L}$, the shunt capacitance $\mathrm{C}$ and the conductance $\mathrm{G}$.

- The resistance R exists due the fact that every conductor has an opposition to the flow of the current.

- The inductance L exists because of the fact that the conductor which is carrying the current is surrounded by a force of the magnetic lines that appear around the conductor.

- The capacitance of the line $\mathrm{C}$ exists because of the fact that the carrying current conductor will form a capacitor with the earth. This capacitance will always be at lower potential which means that the conductor and the earth will form the parallel plates of the capacitor, and the air between them will form the dielectric material.

- The shunt conductance $\mathrm{G}$ exists because of the fact that there is a leakage current over the surface of the insulators. This is especially so when the weather is bad. In addition to this the line impedance will force the voltage drop in the line in quadrature with the current which is flowing in the conductor. This can be found using the equation $2 \pi \mathrm{fLI}$ volts where $\mathrm{f}$ is the supply frequency in $\mathrm{Hz}, \mathrm{L}$ is the inductance per conductor in Henry and $\mathrm{I}$ is the current in the conductor in Ampere.

- The line capacitance has an effect which produces a current that is called the charging current and it is in quadrature with the voltage. The maximum value of the charging current is at the sending end of the line and it will decrease continuously 
until it reaches zero at the receiving end of the line. The value of the charging current IC at the sending end can be obtained by using the equation $2 \pi \mathrm{fCVs}$ where $\mathrm{f}$ is the supply frequency in $\mathrm{Hz}, \mathrm{C}$ is the capacitance in Farad and Vs is the voltage at the sending end to neutral in Volt.

- The shunt conductance is in parallel with the system but the leakage currents are small and the shunt conductance $G$ is consequently ignored in the calculations. Both of the equations given above i.e. the reactive drop $(2 \pi \mathrm{fLI})$ and the charging current $(2 \pi \mathrm{fCVs})$ are proportional to the supply frequency. It is for this reason that they have more influence on the performance of a $50 \mathrm{~Hz}$ line than the performance of the $25 \mathrm{~Hz}$ line. Furthermore, the effects of reactance of the overhead line are more important because of the wide spacing of conductors. However in the case of underground lines, the effects of the reactance are small and the effects of the capacitance are the dominant part.

\section{1- SIMULATED EXPERIMENT 1: FERRANTI EFFECT}

All long transmission lines have large capacitances and inductances which are always represented in their equivalent circuits. When a transmission line is open-circuited or when a very light load is connected at the receiving end, the voltage at the receiving end becomes higher than the voltage at the sending end. This phenomenon is called Ferranti effect. If an alternating voltage is applied, there will be a current that flows into the capacitor which is called charging current or the capacitive current.

The reason that the Ferranti effect occurs is because of the fact that long transmission lines have Capacitance and inductance which are the main parameters. In these transmission lines, the capacitance does not exist in particular points but it is distributed evenly along all the line. If a voltage is applied at the sending end, there will be a current which will be drawn by the capacitance of the line which is larger than the load current. This is why that at no load or light load, the voltage at the receiving end is larger than at the sending end. The units and their connections are shown in figures 1, 2 and 3.

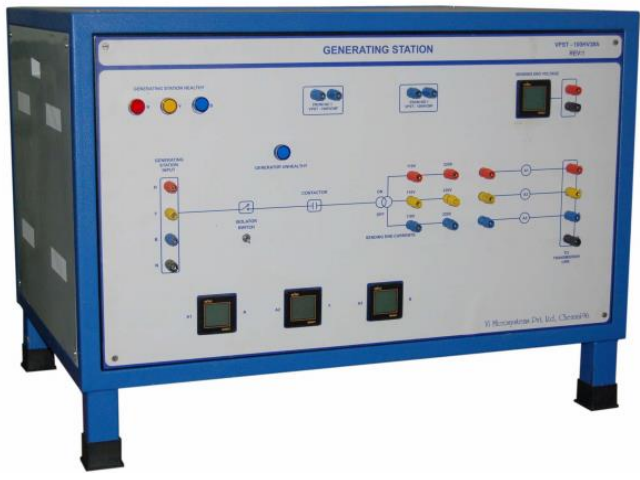

Figure 1. Generating Station of simulator

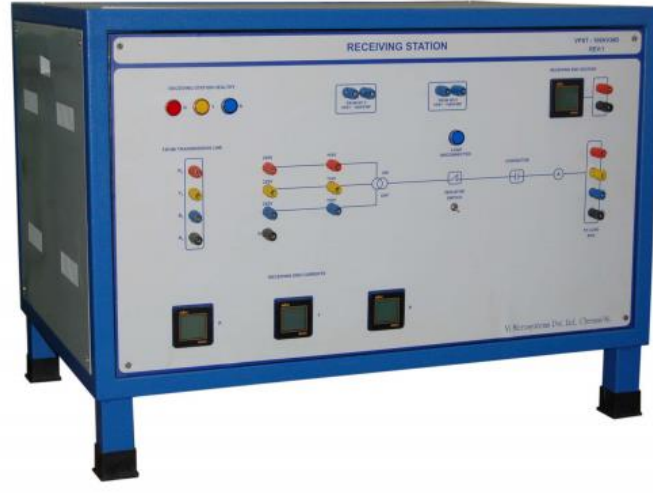

Figure 2. Receiving station of simulator

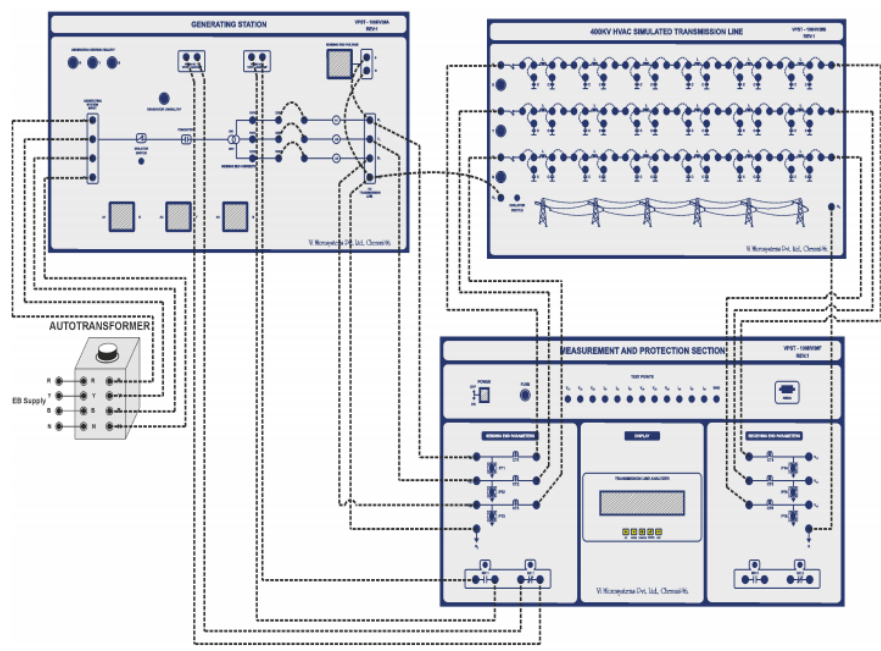

Figure 3. Ferranti effect of a nominal pi $(\pi)$ model:

The nominal PI model of a transmission line at no-load is shown in figure 4 . The phasor diagram of the circuit is shown in figure 5. OE represents the receiving end voltage, $\mathrm{OH}$ represents the current through the capacitor at the receiving end and EF is the voltage drop across R. The voltage drop across the inductor is represented by FG and OG represents the sending end voltage at a no-load.

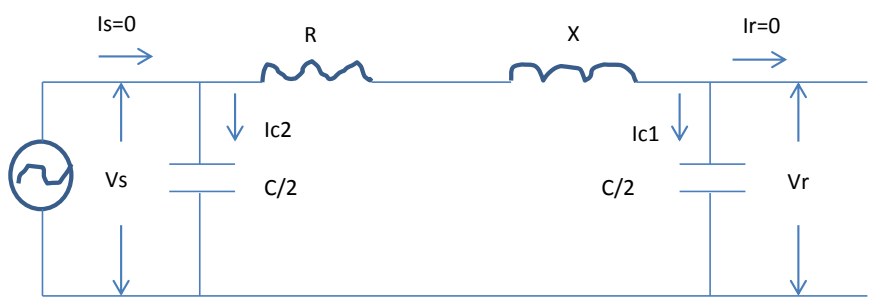

Figure 4.Nominal PI Model of a transmission line at no-load 


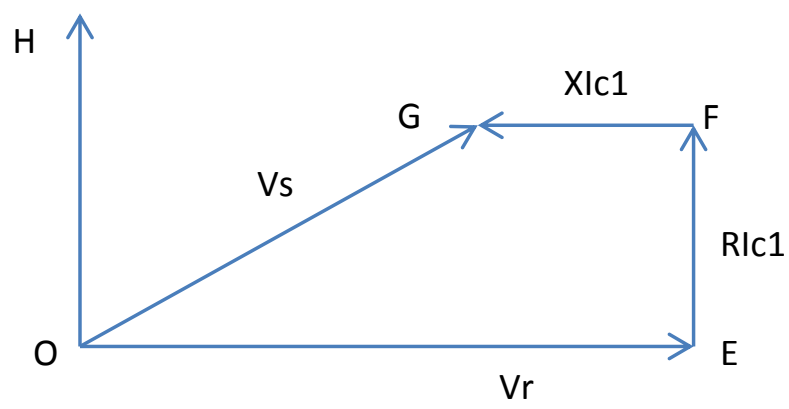

Figure 5. Phasor Diagram of the circuit

The diagram shows that $\mathrm{OE}$ is larger than OG which means that at no-load the voltage at the receiving end is greater than the voltage at the sending end. For the nominal pi $(\pi)$ model shown in figure 4

$$
\mathrm{Vs}=(1+\mathrm{ZY} / 2) \mathrm{Vr}+\mathrm{Z} \mathrm{Ir}
$$

It is clear that at no load, Ir $=0$ because the receiving end is open-circuited.

$$
\begin{aligned}
& V s=(1+Z Y / 2) V r \\
& V s-V r=(1+Z Y / 2) V r-V r \\
& V s-V r=V r[1+Y Z / 2-1] \\
& V s-V r=(Y Z / 2) V r \\
& Z=(r+j w l) s \\
& Y=(j w c) s
\end{aligned}
$$

If the resistance of the transmission line is neglected the above equation becomes:

$$
\begin{aligned}
& Z=j w l s \\
& V s-V r=\frac{1}{2}(j w l s)(j w c s) V r \\
& V s-V r=-\frac{1}{2}\left(w^{2} s^{2}\right) l c V r
\end{aligned}
$$

And if the transmission line is an overhead line, the velocity of propagation of electromagnetic waves on the transmission lines is given by:

$$
\begin{aligned}
& 1 / \sqrt{ } l c=3 \times 10^{8} \mathrm{~m} / \mathrm{s} . \\
& \sqrt{l c}=\frac{1}{3} \times 10^{8} \\
& L c=1 /\left(3 \times 10^{8}\right)^{2} \\
& V s-V r=-\frac{1}{2} w^{2} s^{2}\left(1 /\left(3 \times 10^{8}\right)^{2} V r\right.
\end{aligned}
$$

Where $w=2 \pi f$

$$
\left.V s-V r=-\left(\left(4 \pi^{2}\right) / 18\right) \times 10^{-16}\right) f^{2} s^{2} V r
$$

From this equation it is shown that that $(\mathrm{Vs}-\mathrm{Vr})$ is negative which means that $\mathrm{Vr}>\mathrm{VS}$. The equation shows that the Ferranti effect depends on the voltage frequency and the length of the transmission lines. From the theory of transmission lines and in particular the ABCD parameters the sending end voltage can be given by:

$$
V s=A V r+B I r
$$

And if there is no load at the receiving end,

$$
\begin{aligned}
& I r=O, V r=V r n l \\
& V s=V r n l \\
& |V r n l|=\frac{|V s|}{|A|}
\end{aligned}
$$

Where $\operatorname{Vr} n l=$ Voltage at the receiving end at no load. If the transmission line is long i.e. of a length of $250 \mathrm{Km}$ or above, $\mathrm{A}<1$, and it will decrease more if length of the transmission line increases further. As a result of this it is clear from the above equation that $V r n l>V s$ ). When the length of the transmission line increases further $\mathrm{Vr}$ nl becomes much larger.

The Ferranti effect was examined for a range of phase voltage of 53-224 $\mathrm{V}$ and a line voltage of the range 93-389 V. It is clear from the results shown in tables 1-5 shown below that the decrease of the receiving voltage is always less than $10 \%$ for the chosen range. The largest decrease occurs at $100 \mathrm{~V}$ which is about $6 \%$. As the sending voltage increases further, the reduction becomes smaller and going down to less than $1 \%$ at a sending voltage of $224 \mathrm{~V}$. Figure 9 Shows the voltage at the receiving end has increased from 203 to 206 volts.

\section{REDUCING THE FERRANTI EFFECT}

It is a fact that all electrical equipments are designed to operate at a specific voltage. Therefore if the voltage at the receiving end, i.e. the user end becomes higher than the specific value for that particular device, it could be damaged. At low load or no-load the Ferranti effect can be controlled by placing shunt reactors at the receiving end of the lines. This shunt reactor is an inductive current element which is connected between line and neutral in order to compensate the capacitive current from transmission lines. These reactors will compensate the capacitive VAr of the lines in order to regulate the voltage and keep it at a certain range. The units used for all nine experiments of the course are shown in figures 6,7 and 8 .

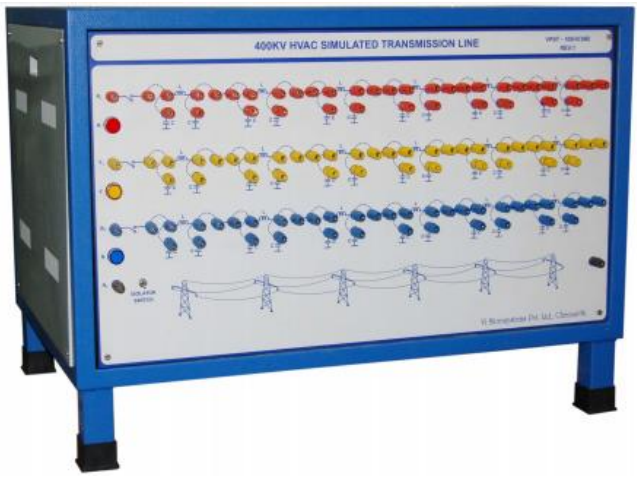

Figure 6. Transmission line unit

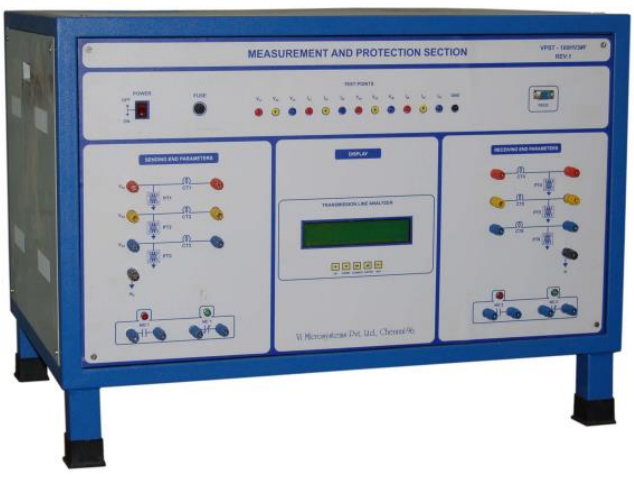

Figure 7.Measurement and protection unit 


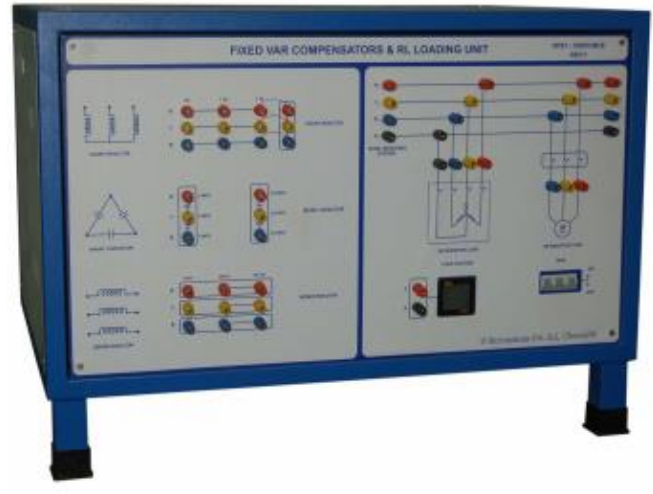

Figure 8. Compensator unit and RLC loading section

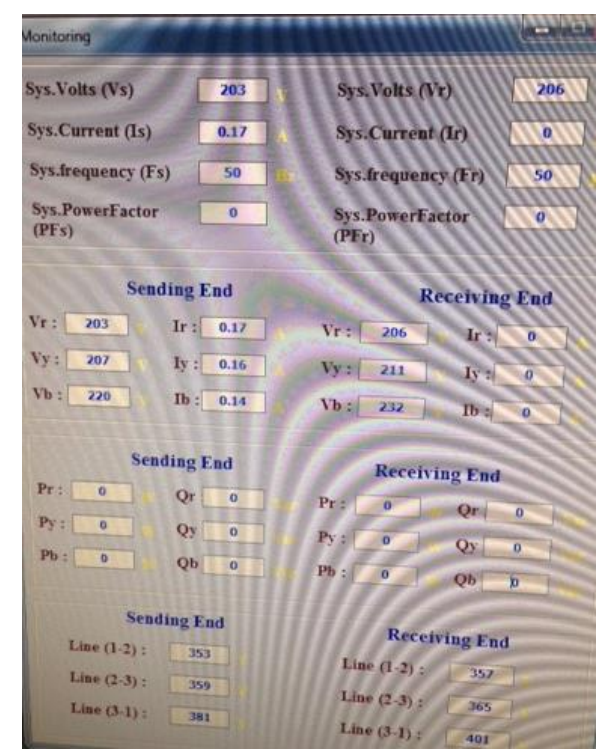

Figure 9. Simulation readings at a sending voltage $=203 \mathrm{~V}$

\section{2- SIMULATED EXPERIMENT2: ABCD PARAMETRS}

In transmission lines different types of losses occur during the transmission process. This of course will result in reduction of efficiency and in order to improve the efficiency two port networks should be used.

A two port network has two inputs and two outputs as shown in figure 10. Vs and Is are the sending end voltage and current and $\mathrm{Vr}$ and $\mathrm{Ir}$ are the voltage and the current at the receiving end. A, B, C and D are called the $\mathrm{ABCD}$ parameters of a transmission line

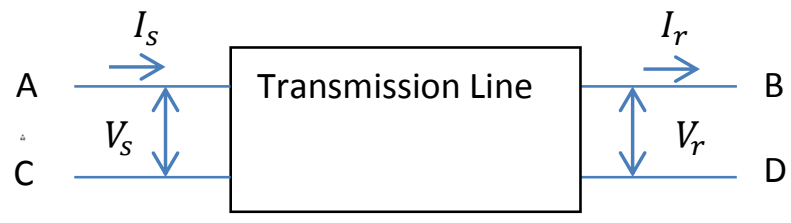

Figure 10. Two port network

The voltage and current at both the sending and receiving ports are related by the equation:

$$
V s=A V r+B I r
$$

$$
I s=C V r+D I r
$$

Where Vs is sending end voltage, Is is sending end current, $\mathrm{Vr}$ is receiving end voltage and Ir is receiving end current.

$\mathrm{A}, \mathrm{B}, \mathrm{C}$ and $\mathrm{D}$ are the transmission parameters and they are used for the analysis of an electrical network and for determining the performance of input, output voltage and current of the transmission line. The parameters equation can also be written as:

$$
\left[\begin{array}{l}
V s \\
I r
\end{array}\right]=\left[\begin{array}{ll}
A & B \\
C & D
\end{array}\right]\left[\begin{array}{c}
V r \\
I r
\end{array}\right]
$$

This matrix is called the transmission matrix of the network.

1- ABCD parameters (open circuit)

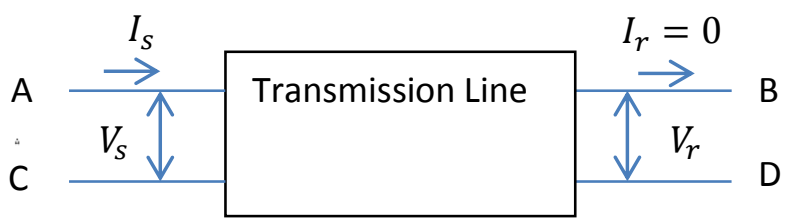

Figure 11. Two port network (open circuit)

As shown in figure 11, if the output terminals are open Ir is zero, and the voltage measure across them is $\mathrm{Vr}$ and the equation become:

$$
\begin{aligned}
& V s=A V r+B O \\
& V s=A V r+0 \\
& A=\frac{V s}{V r} \mid I r=0
\end{aligned}
$$

The constant $\mathrm{A}$ is a dimensionless constant because it is the result of the division of voltage over voltage.

The same can be repeated to the second equation i.e. if $\mathrm{Ir}=0$ the second equation becomes,

$$
\begin{aligned}
& I s=C V r+D O \\
& I s=C V r+0 \\
& C=\frac{I s}{V r} \mid I r=0
\end{aligned}
$$

The unit of $\mathrm{C}$ is Siemens.

\section{2- $A B C D$ parameters (short circuit)}

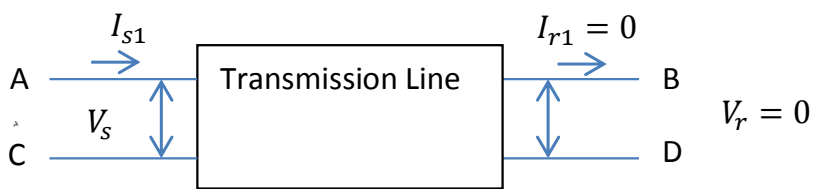

Figure 12. Two port network (short circuit)

If the receiving end is short-circuited, the first equation becomes:

$$
\begin{aligned}
& V s=A O+B I r \\
& V s=O+B I r \\
& B=\frac{V s}{I r} \mid V r=0
\end{aligned}
$$

The unit of B is Ohms. This is shown in figure 12 and the second equation becomes

$$
\begin{aligned}
& I s=C O+D I r \\
& I s=O+D I r \\
& D=\frac{I S}{I r} \mid V r=0
\end{aligned}
$$

The parameter $\mathrm{D}$ is a dimensionless constant. 
3- $A B C D$ parameters and relationship between them If the voltage $\mathrm{V}$ is applied to the sending end, and the receiving end is kept short-circuit, so the voltage becomes zero as shown in figure 13.

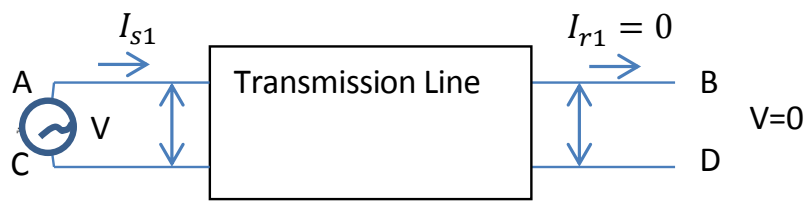

Figure 13. Two port network

From the parameters equation, the voltage and current equations become

$$
\begin{aligned}
& V=B I_{r 1} \\
& I_{s 1}=D I_{r 1}
\end{aligned}
$$

If the voltage is applied at the receiving end, the direction of the current in the network changes as shown in figure 14.

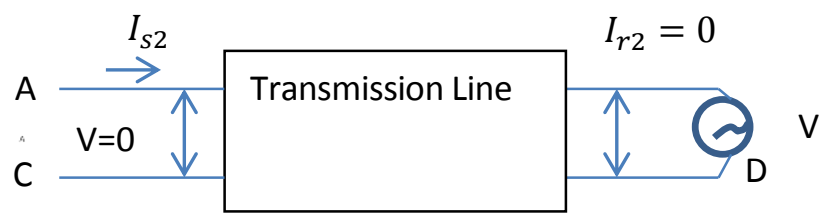

Figure 14. Two port network

The parameters equations become:

$$
\begin{aligned}
& 0=A V-B I_{r 2} \\
& I_{r 2}=\frac{A V}{B}
\end{aligned}
$$

And also

$$
-I_{s 2}=C V-D I_{r 2}
$$

The circuit contains only passive components and consequently the current remains same Is = Ir. By using the above equations this will result in,

$$
\begin{aligned}
I_{s 2} & =I_{r 2} \\
-I_{r 1} & =\mathrm{CV}-\frac{D A V}{B}
\end{aligned}
$$

By dividing the above equation by $-\mathrm{V} / \mathrm{B}$ this will result in:

$$
A D-B C=1
$$

If the circuit is symmetrical, the input and output terminal can be interchanged without any effect on performance of the circuit.

$$
\begin{aligned}
& V=B I_{r 1} \\
& I_{s 1}=D I_{r 1}
\end{aligned}
$$

When the circuit is supplied from the sending end and the receiving end is short-circuited, the impedance becomes

$$
Z_{s 1}=\frac{V}{I_{s S}}=\frac{B}{D}
$$

When the sending end is short-circuited and the voltage is supplied from the receiving end, the impedance becomes:

$Z_{s 2}=\frac{V}{I_{r 2}}=\frac{B}{A}$ and if the circuit is symmetrical, this results in:

$\frac{B}{D}=\frac{B}{A}$

$$
Z_{s 1}=Z_{s 2}
$$

$A=D$

The result of the simulation and its power circle diagram for a voltage of 120 at the sending end are shown figure 15 . The results include true power, reactive power and the real power. Figure 16 gives the ABCD parameters which can be obtained both manually or by Auto mode.

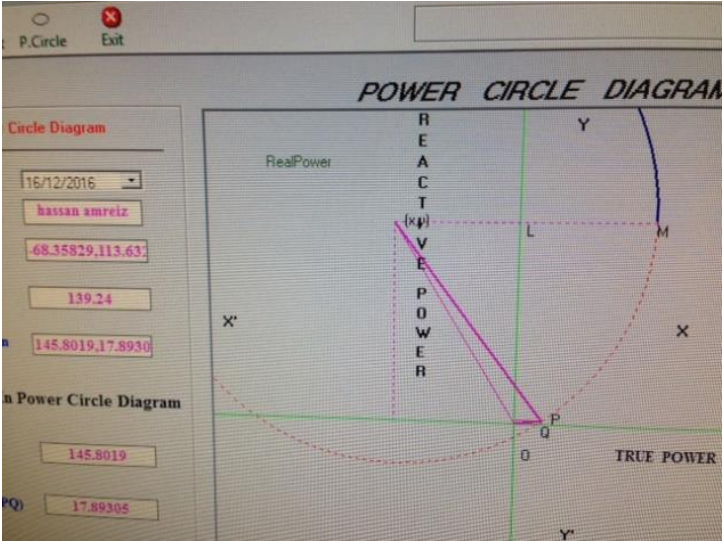

Figure .15 Power Circle diagram

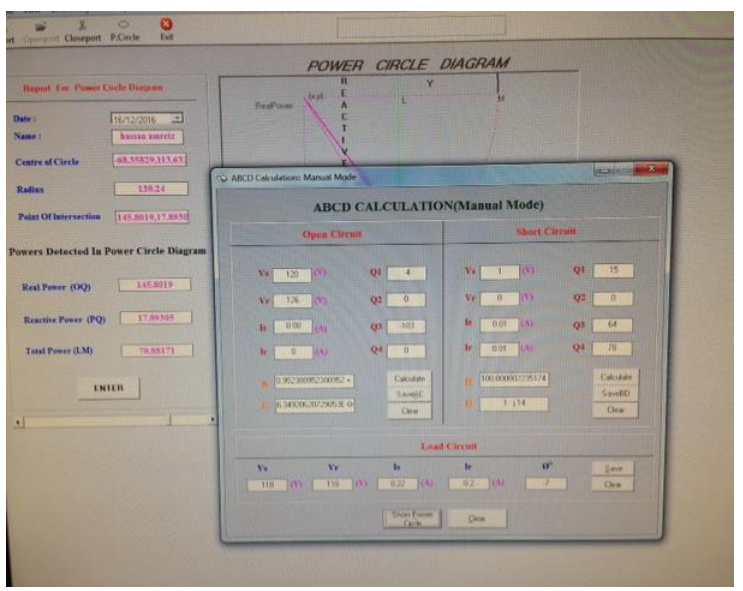

Figure 16. ABCD values at $120 \mathrm{~V}$ (Manual mode)

3- Simulated Experiment 3:Surge Impedance Loading

Transmission lines consist of capacitance and reactance which are called distributed parameters and are distributed uniformly along the transmission line. If a voltage drops occur in transmission line because of the inductance, it will be compensated by the capacitance of this transmission line.

In this case if the transmission line generates capacitive reactive volt-amperes an absorbing reactive volt-amperes will be produced in the series inductance. If the two values are equal and opposite, the load in this case is called surge impedance load (SIL). This load sometimes is called the natural load as the power dissipated in the transmission process is zero. In addition to this both the voltage and current are always in phase and if the surge impedance of the transmission line has ended, the power delivered in this case is called surge impedance loading. When the circuit breaker is closed, the shunt capacitance will charge the transmission line. $\mathrm{V}$ is the phase voltage at the receiving end, $\mathrm{L}$ is the series inductance per phase, $\mathrm{X}_{\mathrm{L}}$ is the series inductance reactance per phase, $\mathrm{X}_{\mathrm{C}}$ is the shunt capacitance reactance per phase and $Z_{o}$ is the surge impedance loading per phase The generated capacitive voltamperes (VAr) in the transmission line is given by: $\left(V^{2}\right) /(X c)=\left(V^{2}\right) w c$ per phase

When the sending and receiving end terminals are closed, the inductance of the transmission line will consume the electrical 
energy and the inductive reactive volt-amperes (VAr) absorbed by the transmission line is given by:

$$
I^{2} X l=I^{2} W l
$$

At natural load, there will be no reactive power, and the load becomes totally resistive and in this case the surge impedance loading per phase is calculated as follows:

$$
\begin{aligned}
& V^{2} w C=I^{2} w L \\
& \frac{V}{I}=\frac{\sqrt{L}}{\sqrt{C}}=Z_{0}
\end{aligned}
$$

The surge impedance loading can also be defined as the power load when the total reactive power of the transmission line becomes zero because the capacitive power will be consumed by the series inductance of the transmission line. If Po is its natural load of the lines, the phase surge impedance loading $(\mathrm{SIL})_{1} \varnothing$ is given by:

$$
(S I L)=P_{0}=V_{p} I_{p} \cos \emptyset
$$

Because the load is totally resistive in this case then as a consequence,

$$
\begin{aligned}
& \cos \emptyset=1 \\
& P_{0}=V_{p} I_{p}=V_{p} \frac{V_{p}}{Z_{0}}
\end{aligned}
$$$$
P_{0}=\frac{V_{p}^{2}}{Z_{0}} W / \text { phase }
$$

Where $V p$-phase voltage.

Line voltage $=V_{L}=\sqrt{3} V_{p}$

$$
(S I L)_{3 \emptyset}=3 P_{0}=\frac{3 V_{p}^{2}}{Z_{0}}=\frac{V_{L}^{2}}{Z_{0}} W
$$

When $\mathrm{kVL}$ in Kilo-Volt is the receiving end voltage, the threephase surge impedance loading is given by:

$(S I L)_{3 \varnothing}=\frac{(K V)_{L}^{2}}{Z_{0}} M W$. The results of the simulations of the surge impedance loading at $150 \mathrm{~V}$ are shown in figure 17.

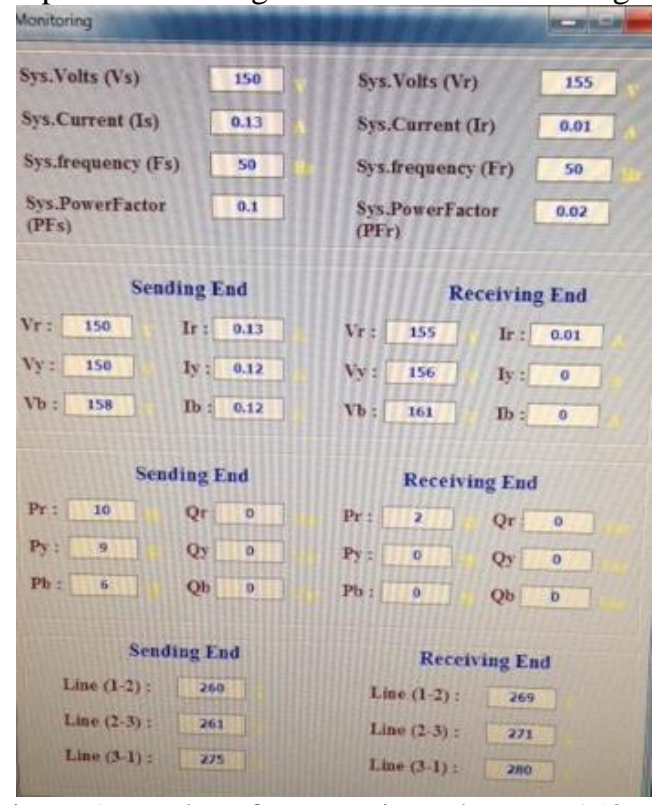

Figure 17. Values for surge impedance at $150 \mathrm{~V}$

Surge impedance loading (SIL) always depend on the voltage of the transmission line and in practice it is always less than the capacity of the maximum loading of the transmission line. When $S I L<$ load, reactive volt-amperes are generated, and the voltage at the receiving end $\mathrm{Vr}>\mathrm{Vs}$. However if SIL > load, the voltage at receiving end $\mathrm{Vr}<\mathrm{Vs}$ because the transmission line will absorb the reactive power. When the shunt conductance and resistance are neglected and SIL= load and consequently $\mathrm{Vr}=\mathrm{Vs}$. SIL is the ideal load in the transmission line because both the current and the voltage are uniform along the transmission line. They are also in phase because the generated reactive power $=$ consumed reactive power by the transmission line.

\section{Conclusions}

Asimulation analyser has been used at both undergraduate and postgraduate levels to analyse and investigate a a three-phase HVAC transmission line of length of $180 \mathrm{~km}$ and a single phase line of length of $540 \mathrm{~km}$. The simulator is used to carry nine experiments but only three are reported in this paper.

The Ferranti effect was examined for a range of phase voltage of $53-224 \mathrm{~V}$ and a line voltage of the range $93-389 \mathrm{~V}$. The results showed that the decrease of the receiving end is always less than $10 \%$ for the chosen range. The largest decrease occurs at $100 \mathrm{v}$ which is about $6 \%$. As the sending voltage increases further, the reduction becomes smaller and going down to less than $1 \%$ at a sending voltage of $224 \mathrm{~V}$. The result of the simulation of the ABCD parameters was obtained as power circle values for a voltage of 120 at the sending end. The results included true power, reactive power and the real power. The $\mathrm{ABCD}$ parameters are obtained from the power circle which were obtained from the simulator both manually and by an auto mode.

Surge impedance loading (SIL) always depend on the voltage of the transmission line and in practice it is always less than the capacity of the maximum loading of the transmission line.

\section{References}

[1] Thomas J. Overbye .Using research results for power system classroom education: A power flow and transient stability case study.2009 IEEE Power \& Energy Society General Meeting Year: 2009 Pages: 1 - 3

[2] Electric Power Engineering Education Resources 2005-2006 IEEE Power Engineering Society Committee Report. The Power Engineering Education Committee (PEEC) Task Force on Educational Resources.

[3] J. McCalley ; L. Bohmann ; K. Miu ; N. Schulz. IEEE Transactions on Power Systems Year: 2008 Volume: 23 , Issue: 1 .Pages: $1-24$

[4] Guangye Si ; Julien Cordier ; Ralph M. Kennel. Extending the Power Capability With Dynamic Performance of a Power-Hardware-in-theLoop Application-Power Grid Emulator Using "Inverter Cumulation" IEEE Transactions on Industry Applications Year: 2016 Volume: 52 , Issue: 4Pages: $3193-3202$

[5] Mussa Sheboniea, Mohamed Darwish, Al Janbey. Investigation and Regression Analysis of Weekly Household Appliances in the UK. Mussa Sheboniea, Mohamed Darwish, Al Janbey, International Journal on Energy Conversion (IRECON), Vol.5, N3, May 2017.

[6] Mussa Sheboniea, Mohamed Darwish, Al Janbey. Load Profile of a Typical Household Appliances and Potential Load Shifting in the UK. International Journal on Energy Conversion (IRECON), Vol.4, N5, September 2016.

[7] C. Portela and M.C.tavaros. Modelling, simulation and optimization of transmission lines. Applicability and limitation of some used procedures.

[8] Manul of hvac transmission line analyzer. VPST 100HV3. Vi Microsystems Pvt. Ltd.

[9] www.circuitglobe.com 
